\title{
A STUDY OF THE EFFECT OF HYDROGEN SULFIDE ON CONVENTIONAL AND RESIN-MODIFIED GLASS-IONOMER DENTAL CEMENTS
}

\author{
J. OTULAKOWSKA-SKRZYNSKA*, B. CZARNECKA**, "J. W. NICHOLSON***, ${ }^{* * * *}$ \\ *Department of Prosthetic Dentistry, Poznań University of Medical Sciences, Poznań, Poland \\ **Department of Biomaterials and Experimental Dentistry, Poznań University of Medical Sciences, Poznań, Poland \\ ***Dental Materials Unit, Queen Mary University of London, London UK. \\ ****Bluefield Centre for Biomaterials, London, UK \\ \#E-mail: John.Nicholson@bluefieldcentre.co.uk
}

Submitted April 10, 2017; accepted July 29, 2017

\begin{abstract}
Keywords: Glass-ionomer, Hydrogen sulfide, Effects
The effect of aqueous hydrogen sulfide on the properties of a conventional and a resin-modified glass-ionomer dental cement has been determined. Specimens were stored for 1 week in (i) $\mathrm{H}_{2} \mathrm{~S} /$ glycerol/water, (ii) glycerol/water and (iii) pure water. After this time, the mass changes were determined, the $\mathrm{pH}$ of the solution was measured and the ion-content was determined, the latter by ICP-OES. There were significant differences in the mass uptake, pH change and ion release of the cements. Both showed significant gains in mass in both water and water/glycerol. In $\mathrm{H}_{2} \mathrm{~S} /$ water/glycerol Ketac Cem (a conventional glassionomer) showed an insignificant mass loss, and Fuji Plus showed a minor significant gain. Both materials altered the pH of all storage solutions significantly. The $\mathrm{pH}$ of the $\mathrm{H}_{2} \mathrm{~S} /$ water/glycerol medium increased whereas the $\mathrm{pH}$ of both pure water and water/glycerol went down. The ion release into glycerol/water was different from release into water, with sodium release being suppressed. The $\mathrm{H}_{2} \mathrm{~S}$ medium showed almost no differences from glycerol/water, indicating that the $\mathrm{H}_{2} \mathrm{~S}$ component has almost no effect on these cements. This leads to the conclusion that these cements can safely be used sub-gingivally even in patients where oral malodour suggests that reasonable amounts of $\mathrm{H}_{2} \mathrm{~S}$ may be present.
\end{abstract}

\section{INTRODUCTION}

Glass-ionomers, both conventional and resin-modified, are widely used in dentistry, both as full restorative materials and as liners below other restoratives [1]. They are ceramic-based materials, prepared from special ionleachable glaaes by reaction with aqueous poly(acrylic acid). In the case of the resin-modified glass-ionomer, this setting reaction is augmented by a polymerization process involving the additional monomer 2-hydroxyethyl methacrylate (HEMA). Both of these cements release ions such as $\mathrm{F}, \mathrm{Na}, \mathrm{Ca}, \mathrm{Sr}, \mathrm{Al}, \mathrm{Si}$ and/or $\mathrm{P}$ depending on cement composition and conditions [2-4]. Ion-release varies with $\mathrm{pH}$, and generally increases at lower $\mathrm{pH}$ due to attack by the external acid solution on the surface of the cement, and embedded unreacted glass particles within that surface.

Like other ions, under acidic conditions the total amount of fluoride is increased. However the amount of free fluoride, i.e. discrete $\mathrm{F}^{-}$ions, is significantly reduced $[3,4]$. This appears to be related to the increase in aluminium under acidic conditions, and the formation of complex species such as $\mathrm{AlF}_{6}{ }^{3-}$, or other fluoro-alumino species, such as $\mathrm{AlF}_{2}^{+}$and $\mathrm{AlF}^{2+}$, as suggested by Crisp and Wilson [5].
The acidic conditions used in studies to date have been created by the presence of lactic acid. This is the acid that is mainly responsible for dental caries [6], and is also the acid that has been used in erosion testing of cements [7]. However, it is not the only acid that may be present in the mouth. Other organic acids, such as ethanoic (acetic) and propionic acids, are known to be associated with caries, though they tend to occur at much lower concentrations that lactic [6]. In addition, hydrogen sulfide is known to occur under certain conditions.

Hydrogen sulfide has been shown to be associated with halitosis in patients $[8,9]$. It arises in the mouth from the metabolism of gram-negative bacteria, such as Porphyromonas gingivalis, Prevotella intermedia, Fusobacterium nucleatum, Treponema denticola and Veillonella alcalescens, acting on proteinaceous substrates [10]. This is favoured by anaerobic conditions, and leads to the occurrence of oral malodour. Oral malodour is also known to be linked to periodontitis in adults [11]. The bacteria responsible for such malodour are similar to the bacteria that cause periodontitis, and the presence of $\mathrm{H}_{2} \mathrm{~S}$ itself may damage the tissues of the mouth and lead to periodontal disease [12].

Hydrogen sulfide is known to cause problems for materials, used in dentistry especially metals. Noble 
metals typically tarnish in the mouth, an effect that has been attributed to the effect of $\mathrm{H}_{2} \mathrm{~S}[13,14,15]$. Alloying such metals with palladium eliminates this effect, because palladium has a much lower affinity for sulfur compounds than have gold or silver. Traditional amalgam fillings are also likely to be tarnished by hydrogen sulfide, due to the well known affinity of mercury for sulphur compounds [15], though this has received very little attention in the literature.

Exposure to $\mathrm{H}_{2} \mathrm{~S}$ has also been shown to alter the crystal structure of natural hydroxypatite at enamel surfaces [8]. Studies have shown that sustained action of this compound caused the surface to develop a roughened and coarse morphology. This attack was also shown to trigger a loss of crystal structure that may potentially lead to observable tooth wear. However, no differences were shown in bond strength to a self-etching bonding strength in shear mode [8], suggesting that adhesion can be maintained, despite loss of crystal structure.

Hydrogen sulfide is a weak acid. It dissociates in water to generate hydrated hydrogen ions, $\mathrm{H}^{+}{ }_{(\mathrm{aq})}$, and hydrosulfide anions, $\mathrm{HS}_{(\mathrm{aq})}^{-}$. The $\mathrm{pK}_{\mathrm{a}}$ for this first dissociation is 6.89 [16]. There is a second possible dissociation, ie

$$
\mathrm{HS}_{(\mathrm{aq})}^{-} \rightarrow \mathrm{H}^{+}{ }_{(\mathrm{aq})} \cdot+\mathrm{S}_{(\mathrm{aq})}^{2-}
$$

Determining the $\mathrm{pK}_{\mathrm{a}}$ for this step has been difficult to determine experimentally, and is currently considered to be of the order of 18 [17].

Hydrogen sulfide is unstable in water, because it reacts rapidly with dissolved oxygen present to form elemental sulfur [18]. However, it is more stable in saliva due to the presence of naturally-occurring thickening agents, such as mucin, which stabilise it sufficiently for $\mathrm{H}_{2} \mathrm{~S}$ to be reasonably long-lived in the mouth. $\mathrm{H}_{2} \mathrm{~S}$ can also be stabilised in water by the presence of glycerol, so that dissolving it in a 50:50 $\mathrm{H}_{2} \mathrm{O} /$ glycerol co-solvent is a useful way of obtaining long-lived $\mathrm{H}_{2} \mathrm{~S}$ solutions [19].

The present study has been undertaken to determine the effect of hydrogen sulfide on glass-ionomer dental cements designed for use as luting agents. In clinical use, luting cements may come into prolonged direct contact with $\mathrm{H}_{2} \mathrm{~S}$, especially when they are used for permanent cementation of subgingival crowns. This is because anaerobic conditions experienced by the bacterial flora in the subgingival region favour the formation of $\mathrm{H}_{2} \mathrm{~S}$.

In the present study, hydrogen sulfide was employed as a solution in 50:50 $\mathrm{H}_{2} \mathrm{O} /$ glycerol and for completion it was also necessary to study the interaction of cements with $\mathrm{H}_{2} \mathrm{O}$ /glycerol control. Experiments involved the determination of mass changes of the cement specimens during storage, measurement of $\mathrm{pH}$ of these solutions after the storage period, and determining the ion release using ICP-OES.

\section{EXPERIMENTAL}

\section{Materials and Methods}

The two cements used in this investigation were as follows: a conventional glass ionomer luting cement (Ketac-Cem, 3M ESPE, Seefeld, Germany) and a resin modified glass ionomer luting cement (Fuji Plus, GC, Japan).

Cements were mixed according to manufacturers' instructions, allowed to set for 1 hour at $37^{\circ} \mathrm{C}$ in $6 \times 4 \mathrm{~mm}$ moulds, removed and accurately weighed. Six specimens of each type of dental material were individually immersed in $5 \mathrm{ml}$ aliquots of three different storage media. The storage media were: water, water/glycerol and $\mathrm{H}_{2} \mathrm{~S} /$ water/ glycerol, the first two being effectively controls against which behaviour of cements in the acidic medium could be compared.

Hydrogen sulfide needs to be stabilised in water by the addition of glycerol. To do this, a $500 \mathrm{ml}$ volume of $50 / 50 \mathrm{v} / \mathrm{v}$ water/glycerol co-solvent was prepared, using double deionised water (prepared using a Purite RO 200 deioniser) and glycerol (Analytical grade, Acros). Stabilised $\mathrm{H}_{2} \mathrm{~S}$ was prepared by bubbling $\mathrm{H}_{2} \mathrm{~S}$ gas (99.5\% pure, Aldrich) until a $\mathrm{pH}$ of 4.5 was achieved. All $\mathrm{pH}$ measurements were made using an Inolab Level $1 \mathrm{pH}$ meter.

The specimens were stored in these media at $37^{\circ} \mathrm{C}$ for one week. After this time, they were removed, excess surface moisture wiped away and the specimens reweighed. The storage solution was then analysed for metal ion content using ICP-OES and the $\mathrm{pH}$ determined. The ICP-OES calibration curve had an $\mathrm{R}$ value $>0.99$ and all data had $\mathrm{RSD}<1.5 \%$, most of which were below $0.5 \%$.

\section{RESULTS}

The changes in the masses of the specimens immersed in different storage solutions are shown in Table 1. The two different types of glass-ionomer showed significant gains in mass in both water $(\mathrm{p}>0.001)$ and water/

Table 1. Average gain in mass after storage in different solutions for one week (standard deviations in parentheses).

\begin{tabular}{lcccc}
\hline \multirow{2}{*}{ Cement } & \multirow{2}{*}{ Type } & \multicolumn{3}{c}{ Change in mass (\%) } \\
\cline { 3 - 5 } & & $\mathrm{H}_{2} \mathrm{~S} /$ glycerol/water & $\mathrm{H}_{2} \mathrm{O} /$ glycerol & $\mathrm{H}_{2} \mathrm{O}$ \\
\hline Ketac-Cem & conventional & $-0.3(0.4)$ & $1.2(0.3)$ & $3.0(0.7)$ \\
Fuji Plus & resin-modified & $0.4(0.2)$ & $1.3(0.7)$ & $5.5(1.1)$ \\
\hline
\end{tabular}


glycerol $(\mathrm{p}>0.001)$. In $\mathrm{H}_{2} \mathrm{~S} /$ water/glycerol Ketac-Cem showed a minor loss that was not statistically significant, whereas Fuji Plus showed a minor gain that was just about significant $(\mathrm{p}>0.02)$. For both cements, the gain in $\mathrm{H}_{2} \mathrm{~S} /$ glycerol/water was lower by an amount that was significant (to $\mathrm{p}>0.001$ ). Conversely, the gain in pure water was greater than the gain in water/glycerol $(\mathrm{p}>0.001)$.

The two cements showed similar changes in mass to each other in both $\mathrm{H}_{2} \mathrm{~S} /$ glycerol/water and glycerol/ water. In pure water, however, the uptake by Fuji Plus was significantly greater than that by Ketac-Cem $(\mathrm{p}>0.05)$.

The observed changes in $\mathrm{pH}$ are shown in Table 2. Both materials altered the $\mathrm{pH}$ of all storage solutions by amounts that were statistically significant $(\mathrm{p}>0.001)$. In the case of $\mathrm{H}_{2} \mathrm{~S} /$ water/glycerol the cements reduced $\mathrm{pH}$ towards neutral, whereas in both pure water and water/ glycerol, they shifted it slightly to the acidic side of neural by small but significant amounts (to at least $\mathrm{p}>0.01$ ).

Table 2. Values of $\mathrm{pH}$ for different storage media after immersion of specimens for one week (standard deviations in parentheses).

\begin{tabular}{lccc}
\hline \multirow{2}{*}{ Cement } & \multicolumn{3}{c}{$\mathrm{pH}$ value } \\
\cline { 2 - 4 } & $\mathrm{H}_{2} \mathrm{~S} /$ glycerol/water & $\mathrm{H}_{2} \mathrm{O} /$ glycerol & $\mathrm{H}_{2} \mathrm{O}$ \\
\hline None & $4.5(0.1)$ & $6.1(0.1)$ & $7.0(0.1)$ \\
Ketac-Cem & $6.2(0.2)$ & $5.7(0.1)$ & $6.7(0.1)$ \\
Fuji Plus & $5.7(0.1)$ & $5.3(0.1)$ & $6.4(0.1)$ \\
\hline
\end{tabular}

The concentrations of the ions released by the cements into different storage solutions are shown in Table 3. Ion release into glycerol/water was different from ion release into water, with release of sodium in particular being suppressed by an amount that was significant ( $\mathrm{p}>0.001$ ). The $\mathrm{H}_{2} \mathrm{~S}$ medium, by comparison showed

Table 3. Ion release into different media after storage for one week (standard deviations in parentheses).

\begin{tabular}{lrrr}
\hline \multirow{2}{*}{ Cement } & \multicolumn{3}{c}{ Concentration (ppm) } \\
\cline { 2 - 4 } & $\mathrm{H}_{2}$ S/glycerol/water & $\mathrm{H}_{2} \mathrm{O} /$ glycerol & \multicolumn{1}{c}{$\mathrm{H}_{2} \mathrm{O}$} \\
$\mathrm{Al}$ & $15.2(0.4)$ & $14.5(0.1)$ & $13.9(0.2)$ \\
$\mathrm{Ca}$ & $15.5(0.1)$ & $14.6(0.1)$ & $12.7(0.1)$ \\
$\mathrm{Na}$ & $15.0(0.9)$ & $13.4(0.1)$ & $20.8(0.8)$ \\
$\mathrm{P}$ & $2.0(0.9)$ & $0.0(1.9)$ & $0.8(0.2)$ \\
$\mathrm{Sr}$ & $2.1(0.5)$ & $1.9(0.1)$ & $1.8(0.1)$ \\
\hline $\mathrm{Fuji}$ Plus & & & \\
$\mathrm{Al}$ & $16.4(1.4)$ & $16.1(0.8)$ & $17.3(1.8)$ \\
$\mathrm{Ca}$ & $16.1(1.6)$ & $14.8(0.1)$ & $12.6(0.1)$ \\
$\mathrm{Na}$ & $12.6(0.3)$ & $12.6(0.3)$ & $15.1(0.4)$ \\
$\mathrm{P}$ & $2.7(1.5)$ & $0.9(1.8)$ & $0.4(0.8)$ \\
$\mathrm{Sr}$ & $4.7(0.9)$ & $5.3(1.4)$ & $7.1(2.3)$ \\
\hline
\end{tabular}

either no difference or only minor ones compared with glycerol/water. This shows that $\mathrm{H}_{2} \mathrm{~S}$ has almost no effect on solubility of ions, and that the major difference between this storage medium and pure water is due to the presence of glycerol.

\section{DISCUSSION}

Hydrogen sulfide is a weak inorganic acid, as shown by the $\mathrm{pH}$ of the $\mathrm{H}_{2} \mathrm{~S} /$ glycerol/water storage medium $[4,5]$ compared to either glycerol/water or pure water. The $\mathrm{pH}$ value recorded compares closely with those of acids previously used in studies of the interaction of dental restoratives with low $\mathrm{pH}$ media. These acids include substances such as lactic [3], citric and malic $[20,22]$. Results have also been obtained for amino acids [22].

The organic acids that have the most effect on glassionomer cements are chelating acids that typically have a strong affinity for divalent ions, such as $\mathrm{Ca}^{2+}$. This includes lactic, citric and malic acids. The latter two have been shown to be especially erosive towards glassionomer cements, causing them to dissolve completely in approximately 3 months, unlike the mineral acid phosphoric acid [21]. Glass-ionomers stored in the latter acid survived intact, with increased surface hardness and excellent compressive strength [21].

In the present study, hydrogen sulfide has been found to behave more like the amino acids alanine and glycine in their behaviour towards glass-ionomer cements. These acids underwent an alteration in $\mathrm{pH}$ towards neutral, and showed only slight differences in ion release behaviour. The most notable change was that aluminium release appeared to be slightly suppressed by these acids, whereas levels of sodium, calcium and silicon were enhanced. In the present study, sodium release was suppressed in the $\mathrm{H}_{2} \mathrm{~S}$ medium by comparison with water, but not compared with the water/glycerol mixture, showing that it is the latter which influences the change in ion release.

The results show overall that hydrogen sulfide has very little influence on the behaviour of glass-ionomer cements in aqueous media, possibly because it does not form chelates with the ions found in these cements. Consequently hydrogen sulphide is not associated with any significant erosion of the cements.

The concentration of hydrogen sulphide in the experimental storage medium can be calculated by neglecting the second dissociation, and assuming all of the $\mathrm{H}^{+}$ions arise from the process:

$$
\mathrm{H}_{2} \mathrm{~S}_{(\mathrm{aq})} \rightarrow \mathrm{H}_{(\mathrm{aq})}^{+}+\mathrm{HS}_{(\mathrm{aq})}^{-}
$$

At $\mathrm{pH} 4.5$, this can be shown to be $7.80 \times 10^{-3} \mathrm{~mol} \cdot \mathrm{dm}^{-3}$, a value which is equivalent to $250 \mathrm{ppm}$. This is considerably greater than the quantities of $\mathrm{H}_{2} \mathrm{~S}$ that have been detected in the breath of 
individuals with oral malodour [23]. Studies have shown variable levels of $\mathrm{H}_{2} \mathrm{~S}$, but all have been of the order of about $1-2$ ppm or less [23]. It is clear that if the elevated levels of $\mathrm{H}_{2} \mathrm{~S}$ used in the present study had little or no effect on glass-ionomer cements, levels occurring clinically are most unlikely to have an effect either.

It is recognised that the experiments reported here lasted for only one week, and that in clinical use, cements need to survive for much longer periods of time, typically several years. However, the absence of any major chemical damage from the elevated levels of $\mathrm{H}_{2} \mathrm{~S}$ employed lead us to conclude that hydrogen sulphide at levels formed in vivo will not adversely affect glassionomer or resin modified glass-ionomer luting cements. These materials can therefore be safely used sub-gingivally to cement crowns and fixed partial dentures.

\section{CONCLUSIONS}

It has been shown that $\mathrm{H}_{2} \mathrm{~S}$ dissolved in a water/ glycerol mixture interacts with glass-ionomer cements (conventional or resin-modified) causing the $\mathrm{H}_{2} \mathrm{~S}$ medium to be buffered, so that values of $\mathrm{pH}$ approached neutral after 1 week. There was little or no gain in mass by cements stored in this mixture, unlike either pure water or the glycerol/water control.

However, unlike other acids, ion release into $\mathrm{H}_{2} \mathrm{~S} /$ water/glycerol did not differ much from ion release into water/glycerol or pure water. The former media showed some suppression of sodium release compared to pure water, but this was the only notable difference. This suggests that $\mathrm{H}_{2} \mathrm{~S}$ interacts only weakly with both types of glass-ionomer cement, and it can be concluded that this substance will have no effect on these materials at levels produced in individuals in vivo. We conclude that glass-ionomer cement (either conventional or resinmodified) can safely be used clinically for subgingival cementation of crowns and fixed partial dentures.

\section{REFERENCES}

1. Mount G.J. (2002). Color Atlas of Glass Ionomer Cement. $3^{\text {rd }}$ ed. Martin Dunitz.

2. Forsten L. (1998): Fluoride release and uptake by glassionomers and related materials and its clinical effect. Biomaterials, 19, 503-508. doi: 10.1016/S0142-9612(97) 00130-0

3. Czarnecka B., Limanowska-Shaw H., Nicholson J.W. (2002): Buffering and ion release by a glass-ionomer cement under near-neutral and acidic conditions. Biomaterials, 23, 2783-2788. doi: 10.1016/S0142-9612(02)00014-5

4. Forss H. (1993). Release of fluoride and other elements from light-cured glass ionomers in neutral and acidic conditions. Journal of Dental Research, 72, 1257-1262. doi: 10.1177/00220345930720081601.
5. Crisp S., Wilson A.D. (1974): Reactions in glass ionomer cements: I. Decomposition of the powder. Journal of Dental Research, 53, 1408-1413. doi: 10.1177/00220345 740530061901

6. Hojo S., Komatsu M., Okuda R., Takahashi N., Yamamda T. (1994): Acid profiles and $\mathrm{pH}$ of carious dentin in active and arrested lesions. Journal of Dental Research, 73, 1853-1857. doi: 10.1177/00220345940730121001

7. Wilson A.D., Groffman D.M., Powis D.R., Scott R.P. (1986): An evaluation of the impinging jet test for the acid erosion of dental cements. Biomaterials, 7, 55-60. doi: 10.1016/0142-9612(86)90090-6

8. Yamaguchi T., Hanabusa M., Hosova., Chiba T., Yoshida T., Morito A. (2015): Enamel surface changes caused by hydrogen sulphide. Journal of Conservative Dentistry, 18, 427-30. doi: 10.4103/0972-0707.168794

9. Nakano Y., Yoshimura M., Koga Y. (2002): Correlation between oral malodor and periodontal bacteria. Microbes and Infection, 4, 679-683. doi: 10.1016/S1286-4579(02) 01586-1

10. Tonzetich J. (1977): Production and origin of oral malodor: a review of mechanisms and methods of analysis. Journal of Periodontology, 48, 13-20. doi: 10.1902/jop.1977.48.1.13

11. Morita M., Wang H.L. (2001): Association between oral malodor and adult periodontitis: a review. Clinical Periodontology, 28, 801-819. doi: 10.1034/j.1600-051x. 2001.028009813.x

12. Ratcliff P.A., Johnson P.W. (1999): The relationship between oral malodor, gingivitis, and periodontitis. A review. Journal of Periodontology, 70, 485-489. doi: 10.1902/ jop.1999.70.5.485

13. Ohta M., Nakagawa M., Matsuya S. (1990): Effect of palladium addition on the tarnishing of dental gold alloy. Journal of Materials Science Materials in Medicine, 1, 140-145. doi: 10.1007/BF00700873

14. Suoninen E., Hero H., Minni E. (2004): Effect on palladium on sulphide tarnishing of noble metal alloys. Journal of Biomedical Materials Research, 19, 917-934. doi: 10.1002/ jbm.820190804

15. Pearson R.G. (1963): Hard and soft acids and bases. Journal of the American Chemical Society, 85, 3533-3539. doi: 10.1021/ja00905a001

16. Giggenbach W. (1971): Optical spectra of highly alkaline sulfide solutions and the second dissociation constant of hydrogen sulphide. Inorganic Chemistry, 10, 1333-1338. doi: 10.1021/ic50112a009

17. Migdisov A.A., Williams-Jones A.E., Lakshtanov L.Z., Alekhun Y.V. (2002): Estimates of the second dissociation constant of $\mathrm{H} 2 \mathrm{~S}$ from the surface sulfidation of crystalline sulfur. Geochemica et Cosmochemica Acta, 66, 1713-1725. doi: 10.1016/S0016-7037(01)00896-1

18. Gal J-Y., Fovet Y., Adib-Yadzi M. (2001): About a synthetic saliva for in vitro studies. Talanta, 53, 1103-1115. doi: 10.1016/S0039-9140(00)00618-4

19. Budavari S., O’Neil M.J., Smith A., Henderson P.E., Kinneary J.F. (1996). The Merck Index, $12^{\text {th }}$ edition, Merck \& Co.

20. Nicholson J.W., Gjorgievska E., Bajraktarova B., McKenzie M.A. (2003): Changes in properties of polyacid-modified composite resins ("compomers") following storage in acidic solutions. Journal of Oral Rehabilitation, 30, 601607. doi: 10.1046/j.1365-2842.2003.01041.x 
21. Aliping-McKenzie M., Linden R.W.A., Nicholson J.W. (2003): The physical properties of conventional and resinmodified glass-ionomer dental cements stored in saliva, proprietary acidic beverages, saline and water. Biomaterials, 24, 4063-4069. doi: 10.1016/S0142-9612(03)00282-5

22. Czarnecka B., Nicholson J.W. (2006): A preliminary study of the interaction of glass-ionomer dental cements with amino acids. Dental Materials, 26, 133-137. doi: 10.1016/j. dental.2005.04.008

23. Rodriguez-Fernandez J., Montes-Bayon M., Pereiro R., Sanz-Medel A. (2001): Gas chromatography double focusing sector-field ICP-MS as an innovative tool for bad breath research. Journal of Analytical Atomic Spectrometry, 16, 1051-1056. doi: 10.1039/B103078G 